* Doutor em Direito Público pela Universidade do Vale do Rio dos Sinos (UNISINOS). Mestrado em Desenvolvimento, Especialização em Direito Ambiental e Graduação em Ciências Jurídicas e Sociais (Direito) todas pela Universidade Regional do Noroeste do Estado do Rio Grande do Sul, (UNIJUI). Professor do Mestrado em Direitos Humanos da Universidade Regional do Noroeste do Estado do Rio Grande do Sul (UNIJUÍ). E-mail: mateus. fornasier@gmail.com

** Doutor em Estudos Estratégicos Internacionais (UFRGS), com período de pesquisa na American University (Washington, D.C., EUA). Mestre em Direito pela Universidade do Vale do Rio dos Sinos (UNISINOS). Graduação em Ciências Jurídicas e Sociais. Pontifícia Universidade Católica do Rio Grande do Sul (PUCRS). Professor Adjunto da Universidade Federal do Rio Grande (FURG). Professor Colaborador do Mestrado em Direito e Justiça Social (FURG). Pesquisador do Grupo PRISMA (UFSM) e do Centro de Estudos e Pesquisas sobre Corrupção (UNESP). Pesquisador associado do Observatório de Economia e Gestão de Fraude (OBE GEF), com sede em Portugal. Membro da Red Internacional de Juristas para a Integracíon Americana (RIJIA), com sede no México.E-mail: 1vazferreira@ gmail.com

\section{Complexidade, globalização e regulação jurídica: a conduta das empresas transnacionais e suas possibilidades de normatização}

\author{
COMPLEXITY, GLOBALIZATION AND JURIDICAL \\ REGULATION: CONDUCT OF TRANSNATIONAL \\ COMPANIES AND THEIR NORMATIVE POSSIBILITIES
}

\author{
* Mateus de Oliveira Fornasier \\ ** Luciano Vaz Ferreira
}

Resumo: A análise das possibilidades de regulação da conduta das empresas transnacionais em um cenário hipercomplexo e policontextural, caracterizado pela pluralidade de possibilidades normativas, é o objetivo principal deste artigo. Seu problema de pesquisa é: de que modo é possível afirmar que a conduta de tais empresas é regulável por ordens jurídicas originadas nos mais diversos contextos? Como hipótese, apresenta-se que são reguláveis juridicamente não apenas em ordens nacionais ou internacionais, mas a partir de ordens jurídicas não estatais, mediante um Direito socialmente originado, não decorrente diretamente do Estado.

Palavras-chave: regulação jurídica; globalização; empresas transnacionais.

Abstract: The analysis of possibilities of regulation of conduct of transnational companies in a hypercomplex and polycontextural, characterized by the plurality of normative possibilities, is the main objective of this article. Its research question is: how is it possible to affirm that the conduct of such companies can be regulated by juridical orders originated in very diverse contexts? As its hypothesis, we presented that they can be regulated not only by State juridical orders, through a socially originated Law, that is not directly related to the State.

Keywords: juridical regulation; globalization; transnational corporations. 


\section{INTRODUÇÃO}

O século XX, peculiarmente, se caracterizou pela emergência de empresas transnacionais (ETNs), ocorrência esta que se estende, inclusive, até o início do século XXI - relacionando-se intimamente à globalização. Trata-se de grandes atores cujas comunicações e atos transbordam os tradicionais limites estatais, refletindo-se em uma multiplicidade concomitante não apenas de locais, mas também de vários sistemas sociais (Economia, Política, Mídia de Massa, Ciência, Tecnologia e Direito, etc.).

É bastante relevante estudar, atualmente, as implicações sociojurídicas correlatas a estes novos atores internacionais. As ETNs podem ser entendidas como "qualquer empresa que possui sede em um país e opera em, pelo menos, um país estrangeiro" (WILKINS, 1993, p. 24). Tais organizações se compõem de várias outras empresas estabelecidas em conglomerados cujo âmbito comunicativo (e de produção de sentido) transborda tradicionais limites estatais, sendo dotadas de fluidez tão característica e marcante que, muitas vezes, a regulação exercida apenas pelo poder normativo de entes nacionais ou internacionais não se demonstra eficaz (TEUBNER, 2012, p. 110). As tentativas de regulação da conduta das ETNs mediante normas estatais e internacionais não têm apresentado sucesso, pois se constituem, na maioria das vezes, de meras recomendações. Mas a pesada crítica pública, espraiada globalmente pela mídia, combinada à ação expressiva de movimentos e organizações da sociedade civil tem impulsionado o desenvolvimento, pelas próprias ETNs, de seus códigos de conduta corporativa. Tais códigos privados são aparentemente voluntários e pouco precisos, almejando o estabelecimento de boas relações (para com os consumidores, a opinião pública, etc.). As empresas, com tais normas, se comprometem imprecisamente a regular suas próprias condutas conforme padrões relacionados às áreas objeto de pressão.

O objetivo geral deste artigo é analisar, assim, as possibilidades normativas relacionadas à conduta das ETNs, em um ambiente social hipercomplexo e policontextural - marcado pela multiplicidade de formas comunicativas e deontológicas de mundo. Nesta senda, se dispõe a responder a seguinte questão: como se pode afirmar que as ETNs podem ter suas condutas reguladas por ordens jurídicas das mais diversas origens? A hipótese que busca responder este problema é a seguinte: os comportamentos de tais atores são juridicamente normatizáveis (termo considerado mais amplo em significados, aqui preferível à noção de disciplina, ${ }^{1}$ pois esta se reportaria a contextos jurídicos passados

1 Acerca da Sociedade Disciplinar e da superação da predominância do seu modelo, ver Foucault (2004) e Deleuze (2007). 
bem delimitáveis no tempo e no espaço, mormente ligados ao caráter repressivo) ${ }^{2}$ não apenas pelo Estado ou suas interações (tratados internacionais, convenções, etc.) mas também por normatividades não estatais, atinentes a um Direito socialmente emergente e independente da ação estatal.

Desenvolveu-se este texto em quatro partes. Inicialmente se contextualiza, em linhas gerais, a questão em torno da hipercomplexidade e da policontexturalidade, sendo relevante, para isto, que é difícil sustentar, atualmente, qualquer argumentação sobre a regulação jurídica de âmbitos complexos que se disponha a considerar exclusivamente uma normatividade de lógica estatal, pois há possibilidades lógicas e comunicativas atuais que, em razão da sua fluidez, a estatalidade - mas isto não quer dizer que o Estado tenha sido relegado à obsolescência, ou a uma situação crítica incontornável e derradeira.

Após isto, trata-se de possibilidades territoriais e extraterritoriais de regulação das ETNs. Isto servirá para demonstrar que, apesar de não ser mais a única voz significativa a normatizar condutas na sociedade, o Estado ainda tem crucial importância regulatória - todavia, é necessário rever o seu papel a partir de um ponto de vista que considere a complexidade atual.

Em seguida, o terceiro momento deste trabalho se destina a refletir sobre algumas experiências de regulação da conduta de ETNs por normas de Direito Internacional já implementadas. Com isto, argumenta-se para delinear alguns óbices práticos e teóricos que esta importante via encontra na prática.

Finalmente, intenta-se apresentar, seguindo-se o raciocínio contextualizado na policontexturalidade, na hipercomplexidade e no chamado pluralismo jurídico, os programas normativos internos de conduta das ETNs como verdadeiras ordens jurídicas não estatais - dada a complexificação social e procedimental que estas práticas têm assumido. Com isto, programas internos de compliance, decorrentes, em grande medida, de pressões sociais, bem como outras formas de regulação de condutas destes atores, são apresentadas.

\section{POLIVOCIDADE E PLURALIDADE: REPENSAR A LÓGICA JURÍDICAA PARTIR DA COMPLEXIDADE E DA MULTIPLI- CIDADE DE CONTEXTOS}

A ideia dos operadores e estudiosos do Direito segundo a qual a lei (estatal), de forma simplista e errônea, é eficiente o suficiente para abranger um período de tempo futuro de longa duração, deve ser desmistificada. O tempo

\footnotetext{
${ }^{2}$ Sobre o contexto espaço-temporal do Direito Repressivo, ver Wilke (1999).
} 
da sociedade pós-moderna é rápido e instantâneo, decorrido por meios de comunicação de alta tecnologia e rapidez - enquanto os juristas adstritos à visão linear e estatalista da Modernidade continuam presos à univocidade do texto escrito. Nota-se, portanto, uma defasagem significativa entre as noções de tempo e sociedade na dogmática jurídica e a atual experiência social; um grande paralelismo temporal, dado que os juristas programam normas para longas durações, mas elas não duram, muitas vezes, dias (ROCHA, 2003, p. 197). Aliás, não é rara a aprovação de leis pelo Poder Legislativo quando a matéria dos seus Projetos já está totalmente transformada, na realidade, em relação ao texto (surgindo, assim, leis "nascidas velhas").

Também ocorre, nestes idos, um paralelismo espacial. No mesmo passo que o tempo se torna instantâneo, o espaço se relativiza para as comunicações velozes e deslocamentos economicamente interessantes, mas pode bloqueado com base em antigas justificativas de soberania quando necessário (fluxos migratórios de refugiados e pessoas economicamente desinteressantes) (BAUMAN, 2005, p. 81-116). Duas lógicas territoriais, portanto, convivem: uma que pouco considera as fronteiras jurídico-política soberanas - noção que simplesmente se esvazia de sentido nas comunicações e resultados (e.g. fluxos de dados pela rede mundial de computadores e danos ambientais), e que demonstra serem os Estados incapazes de afirmar sua autoridade diante de novos entes dotados de poder (ETNs, organizações criminosas, etc.) -; e aquela que, principalmente, na política e no Direito se reafirma, quando necessário (persecução de crimes; tributação e regulação de entes e fatos incapazes de se eximirem da lógica estatal).

Agrava-se esta questão a configuração não apenas uma dualidade de lógicas de tempo-espaciais, mas sim, de uma multitude de formas de normatividade e comunicação. Globalmente ocorre uma grande fragmentação de origens de emissões comunicativas sobre várias matérias, em muitas lógicas diversas. A (re)configuração do Direito na globalização está relacionada com a expansão das possibilidades de escolha proporcionada pela complexificação social decorrente da evolução de formas estratificadas de diferenciação social para formas funcionalmente diferenciadas. Este aumento de complexidade torna muito mais contingentes os contextos nos quais cada subsistema funcional opera e decide. A multiplicidade de centros de racionalização de sentido neste cenário faz com que, na esteira da globalização, não mais se pode atribuir uma existência causal unitária aos acontecimentos sociais. 
Ademais, a acelerada fragmentação característica desta época torna permeáveis as fronteiras territoriais para as comunicações.

O Direito também é afetado por esta descrita fragmentação, de tal modo que seu funcionamento efetivo dependa das suas relações para com as outras instâncias sociais. Ou seja, o (sub)sistema jurídico (co)evolui com racionalidades diferentes (de outros sistemas sociais), num cenário em que $o$ Estado não mais detém a univocidade de emanação normativa social. Uma pluralidade de atores sociais diferenciados em papéis e culturas emerge, redundando numa pluralidade de fontes normativas e de sujeitos de direito merecedores de proteção especial (consumidores, refugiados, hipossuficientes, etc.) (ROCHA; ATZ, 2010, p. 109).

Observa-se, com isto, um pluralismo jurídico, que se relaciona à multiplicidade de âmbitos comunicativos produtores de normatividade jurídica. O pluralismo jurídico é a "multiplicidade de práticas jurídicas existentes num mesmo espaço sócio-político, interagidas por conflitos e consensos, podendo ser ou não oficiais e tendo a sua razão de ser nas necessidades existenciais, materiais ou culturais" (WOLKMER, 2001, p. 219).

Prova-se a multiplicidade de ordens jurídicas antagônicas e sobrepostas era bastante encontrável no Direito pré-Estado-Nação, particularmente no Medievo, em que conviviam manifestações normativas concorrentes, oficiais e não oficiais (e.g. costumes locais, foros municipais, estatutos das corporações de ofício, ditames reais, Direito Canônico e Direito Romano) (WOLKMER, 2001, p. 184). Com a centralização do Direito na figura do Estado moderno o fenômeno jurídico passou a ser identificado necessariamente com os atos estatais, negando-se a juridicidade das manifestações não estatais.

No século XX, sociólogos do Direito tais como Ehrlich(1986), Boaventura de Sousa Santos (2000) e Wolkmer (2001) trouxeram novamente a ideia de que o "Direito não se confunde com o Estado", sendo possível a coexistência entre ordens jurídicas não estatais ainda hoje. Na mesma linha, Teubner (2003), baseando-se em Luhmann (2004), desenvolve a ideia de "policontexturalidade", segundo a qual o "Direito é fragmentado em um pluralismo em que o Estado é apenas mais uma de suas organizações" (ROCHA, 2009, p. 18). Sousa Santos exemplifica o pluralismo jurídico contemporâneo: nas regras de um núcleo familiar; na lex mercatória; no Direito indígena (povos tradicionais); no Direito paralelo das comunidades das favelas brasileiras; e, principalmente para os propósitos deste trabalho, nos códigos de conduta empresariais autoproduzidos (SANTOS, 2000, 1987). 
Tal defasagem fática vem na esteira de uma defasagem teórica: a complexidade do mundo faz com que este não mais suporte uma lógica única. Enquanto a lógica aristotélica seria monocontextural (LUHMANN, 1995, p. 61), pois conforme ela apenas o "ser" e o "não ser" são possíveis (ou algo é conforme determinada lógica, ou não o é, de forma que uma terceira opção não seria possível). Esta racionalidade - adstrita a apenas uma contexturalidade se demonstrou muito importante para a história do pensamento, mas se queda insuficiente em um cenário hipercomplexo, repleto de variedade de formas de comunicação, bem como de centros emissores de normatividade (GÜNTHER, 2004, p. 3-4).

Diversas lógicas e códigos comunicativos seriam possíveis em tal ordem de coisas, o que demonstra a emergência de várias contexturalidades, cada qual com seu respectivo código binário "conforme/em desconformidade" - mas que observam uns aos outros. Neste passo, verifica-se uma estrutura multinivelada de lógicas extremamente complexa. "Uma contexturalidade é um domínio lógico de uma estrutura estritamente valorada em dois valores, e sua abrangência é determinada pelo uso do TND [Lógica "Tertium Non Datur", sem terceiro elemento possível]"; mas quando se considera que o Universo deve ser observado como uma "intersecção de um número ilimitado de contexturalidades duplamente valoradas" (GÜNTHER, 2004, p. 6), está-se diante de uma pluralidade de contexturalidades - ou seja, uma situação de policontexturalidade.

Esta ideia poderia ser desenvolvida um pouco mais para além, quando se toma conhecimento da noção de racionalidade transversal para uma conversação entre sistemas. A destruição seria o destino da sociedade moderna multicêntrica, formada por múltiplas esferas conflitantes entre si, se não desenvolvessem mecanismos intervinculantes que possibilitam o aprendizado e a influência recíprocas - os acoplamentos estruturais, os quais viabilizam as interferências entre diversos subsistemas sociais. Estes mecanismos, verdadeiras interpenetrações entre sistemas comunicativos, filtram (excluindo certas influências e facilitando outras) e promovem as influências e os estímulos intersistêmicos recíprocos de maneira duradoura, estável e concentrada, sem que os sistemas mediante eles acoplados percam suas características autonomias (LUHMANN, 1996, p. 121). Aliás, configura-se uma simultânea relação de independência e dependência entre tais sistemas, visto que suas estruturas "passam a ser, mediante os acoplamentos estruturais, relevantes e mesmo 
indispensáveis à reprodução das estruturas de um outro sistema e vice-versa" (NEVES, 2009, p. 35).

Os acoplamentos estruturais permitem a construção de racionalidades transversais (WELSCH, 2000) entre esferas autônomas de comunicação da sociedade mundial, pois são mecanismos que estabelecem intercâmbios de experiência entre diferentes racionalidade parciais, as quais, "conforme o tipo e a singularidade dos respectivos sistemas ou discursos e de acordo com suas relações específicas, variará intensamente na forma e no conteúdo" (NEVES, 2009, p. 38).

Identificar acoplamentos estruturais entre sistemas revela-se estratégia de grande valia num cenário policontextural e hipercomplexo, em que emergem não apenas sistemas comunicativos diferenciados, mas também diversas ordens de caráter normativo; não apenas ordens normativas, mas ordens jurídicas; não apenas ordens jurídicas estatais - ou dependentes da lógica estatal, tais como ordens internacionais (correlatas aos tratados internacionais) e supranacionais (da qual é exemplo significativo a União Europeia), mas também ordens jurídicas não estatais (formadas por laços contratuais entre empresas, numa contexto em que ETNs impõem, via contrato, a seus fornecedores, os próprios códigos de conduta corporativos). O simples raciocínio impositivo linear de uma ordem soberana estatal a condutas dos privados pode ainda perdurar, mas não mais se verifica como absoluta (de modo como fora outrora).

Sempre que dois sistemas comunicativos interconectam, esta interconexão os torna capazes de desenvolver seus próprios mecanismos de aprendizado e influência estáveis e mútuos. Dessa forma, tem-se que os acoplamentos estruturais constituem racionalidades transversais parciais, sendo que cada uma dessas racionalidades está estruturalmente vinculada às racionalidades particulares, parciais (sistêmicas) confrontadas - sendo, portanto, pontes de transição específicas (NEVES, 2009, p. 42).

O entrelaçamento entre o Direito e outros sistemas sociais, ou entre várias ordens jurídicas diferenciadas, que permite a construção de uma racionalidade transversal pelo aprendizado recíproco e pelo intercâmbio criativo pode ser denominado Constituição transversal (NEVES, 2009, p. 115). Este conceito implica em externalização e internalização de informações entre os mais diversos sistemas sociais funcionais que primariamente se reproduzem com fundamento em códigos binários de diferentes formas de comunicação.

Identificam-se, assim, relações entre ordens jurídicas diversas, que ocorrem no interior do mesmo sistema funcional da sociedade mundial atual, o 
Direito - no qual se diferenciam ordens diferenciadas e subordinadas ao mesmo código binário (direito/ não direito), mas com programas e critérios diferentes. Esta diferenciação interna entre ordens jurídicas - que vai para além da segmentação entre ordens estatais - não vem a significar que tais ordens se encontrem desconectadas: há a ligação, por exemplo, entre ordens estatais e internacionais pelo instituto da ratificação; entre ordens estatais, o Direito Internacional Privado tem desenvolvido mecanismos conectivos também.

É peculiar, no entrelaçamento das diversas ordens jurídicas, o fato de haver relativa independência da mediação do sistema político em seu estabelecimento. No âmbito jurídico, são relevantes as "pontes de transições" desenvolvidas diretamente a partir dos respectivos centros dos seus sistemas (os juízes e tribunais) (LUHMANN, 2004, p. 293). Com isto, tem-se que não apenas a sociedade mundial, mas também seu Direito é multicêntrico - e os centros das demais ordens jurídicas constituem periferia para o centro de uma dada ordem (NEVES, 2009, p. 117). O caráter multicêntrico, com certa possibilidade de comunicação entre centro(s) e periferia(s) de maneira a constituir aprendizado, pode se dar entre as mais diversas categorias de ordens: entre Cortes estatais, entre Cortes estatais e internacionais, etc. Mas este diálogo entre centros não pressupõe uma cooperação permanente entre eles, já que vários conflitos são perceptíveis na práxis.

Tem-se, assim, que diferentemente da noção clássica de constitucionalismo, por exemplo (no qual era possível delimitar as problemáticas relacionadas aos direitos e garantias fundamentais e da limitação e organização estatal às fronteiras nacionais), a noção atual do caráter constitucional (o que pressupõe não apenas a constituição de Estados e organizações interestatais, mas também a emergência de novos centros comunicativos de normatividade jurídica, como aquelas que decorrem das ETNs) exige atualmente a consideração da constitucionalização por outras ordens jurídicas (as que versam sobre Direitos Humanos, por exemplo). Deve-se referir a constitucionalismos nacionais, internacionais, supranacionais e transnacionais - os quais dialogam de maneira a estabelecer processos de aprendizado (seja em situações cooperação, seja em situações de conflito entre ordens) (NEVES, 2009, p. 119-121).

\section{AINDA O DIREITO ESTATAL: IMPORTÂNCIA NA REGULA- ÇÃO DAS ETNS}

Apesar de toda a fluidez com que as ETNs operam (o que colocaria suas comunicações, quase automaticamente, no império da lógica acelerada 
e relativizadora do espaço e do tempo), ainda não se pode absolutizar esta posição - já que, em decorrência do próprio gap entre a lógica fluida e a lógica pretensamente bem delimitada no tempo e no espaço decorrente da soberania -, o fato de uma empresa ser caracterizada como transnacional não a coloca automaticamente em uma espécie de "limbo jurídico", habitando em lugar imaginário na qual a longa manus das jurisdições estatais jamais alcança. Todas ETNs submetem-se, no mínimo, a duas ordens jurídicas: do país onde foram constituídas e mantém a sua sede ("país de origem”) e do local onde exercem as suas atividades ("país hospedeiro"). Ambos Estados possuem a liberdade de utilizarem o seu Direito interno (também chamado de nacional ou doméstico) e os mecanismos que garantem a sua aplicação, com objetivo de regular o comportamento destas entidades.

Em primeiro lugar, uma ETN é sempre compelida a adaptar-se ao Direito de um país hospedeiro. Tal situação advém da própria ideia de soberania, que concede a prerrogativa de cada Estado zelar pela ordem em seu território. Neste cenário regulatório, seria possível defender que bastariam que os países hospedeiros aprovassem legislações de controle da atividade empresária e aplicassem contra ETNs da mesma maneira que fazem com as empresas de atuação exclusivamente interna. Com a adesão da proposta por todos os países hospedeiros onde as ETNs exercem suas atividades, cada qual desempenhando o papel de controlar as atividades comerciais que ocorrem em seu território, diminuiriam as possibilidades de condutas indesejadas por estas entidades.

Pensar assim, no entanto, é simplificar o problema. Achar que mais de 200 países, com capacidades, realidades e interesses diversos, fiscalizarão estas empresas da mesma maneira, de forma espontânea e sem qualquer estímulo externo, é utópico, para não dizer ingênuo. Existe hoje uma acirrada disputa por atração de investimento estrangeiro direto que pode forçar a diminuição dos standards regulatórios, em uma espécie de "corrida para o fundo" (race to the bottom $)^{3}$ (GUZMAN, 1998, p. 671-674). De maneira óbvia, o Estado que está

\footnotetext{
A race to the botton ("corrida para o fundo") ocorre quando os países, em um ambiente de competitividade, não regulam determinadas condutas, passando a tolerar práticas ilícitas para se tornarem mais competitivos. No longo prazo, piora a condição de todos os participantes. Em busca de tornar-se receptor de empresas estrangeiras e investimento externo direto, um Estado pode tornar a sua legislação menos rigorosa e mais permissiva a atividades ilícitas, como no caso da proteção ao meio ambiente, na qual é possível diminuir os requisitos para a concessão de licenças. O problema é que em um ambiente de grande competitividade internacional, muitos países podem ser compelidos a seguirem o exemplo e enfraquecerem seus padrões normativos ainda mais.
} 
buscando incessantemente hospedar uma ETN dificilmente promoverá o endurecimento de seus mecanismos de controle em seu território, com medo de ser preterido na hora da escolha. Neste contexto e por estas razões, não se pode esperar grandes feitos por parte dos Estados hospedeiros.

Isto abre a possibilidade para que a regulação da conduta das ETNs ocorra partindo da ação dos Estados investidores, ou seja, aqueles onde estão sediadas estas empresas (DEVA, 2012, p. 50-51). Como estes Estados investidores se beneficiam economicamente desta relação, deveriam ter a responsabilidade de assegurar que suas ETNs não atuem em detrimento do Estado hospedeiro (SORNARAJAH, 2010, p. 159). Outro aspecto positivo é que se trabalharia com um número muito mais reduzido de países e que são detentores de capacidade de impor sanções efetivas. Esta proposta baseia-se na possibilidade de extensão exterritorial da norma nacional para ações realizadas em país estrangeiro.

Brownlie (1997, p. 321-326) colaciona cinco formas dos Estados exercerem o controle jurídico de condutas. A primeira delas baseia-se no "princípio da territorialidade": os Estados controlam todas as ações que ocorrem em seu território; trata-se de uma decorrência de sua soberania. Apesar de a territorialidade ser a regra geral, não existe proibição para um Estado que deseja, unilateralmente, criar norma de natureza exterritorial que regule condutas realizadas no exterior, desde que haja um elemento de conexão que ligue este fato ao seu interesse nacional e não viole a soberania de outrem. No contexto da "extraterritorialidade", pode recorrer-se ao "princípio da nacionalidade" ou "da personalidade ativa", no qual a norma regula as ações realizadas por seus nacionais (pessoas naturais e jurídicas) produzidas no exterior. Pauta-se na ideia de que os cidadãos devem lealdade ao seu país de origem (PIETH, 2007, p. 270). Além disso, pode vincular-se ao "princípio da personalidade passiva" ou "da nacionalidade da vítima", no qual se reprime atos praticados por estrangeiros contra nacionais no exterior; ao "princípio protetor" ou "da segurança", no qual os Estados fiscalizam as ações praticadas no exterior que possam afetar a sua segurança; e por fim, ao "princípio da universalidade", no qual a natureza grave da conduta impõe que todos os membros da comunidade internacional a reprimam ${ }^{4}$.

\footnotetext{
${ }^{4}$ Conforme Robinson (2001, p. 16), "o princípio da justiça universal é baseado na noção de que certos crimes são tão danosos aos interesses internacionais que os Estados podem - ou até mesmo são obrigados a - processar o infrator, independentemente do local do crime ou da nacionalidade do agressor ou da vítima". Delitos como pirataria, escravidão, crimes de guerra, crimes contra a paz, crimes contra a humanidade, genocídio e tortura enquadrar-se-iam nesta categoria (MACEDO, 2001, p. 29).
} 
O exercício da extraterritorialidade é limitado pela vedação de interferência na soberania de outros Estados. Sendo assim, os Estados não estão autorizados, sob o pretexto de cumprir uma norma jurídica nacional de abrangência extraterritorial, adentrar em território estrangeiro sem o consentimento e realizar atos soberanos, como medidas que necessitam de poder de polícia ou jurisdição (PIETH, 2007, p. 269). Em outras palavras, a abrangência extraterritorial da norma nacional não é proibida, podendo regular fatos ocorridos no exterior, mas a sua aplicação e efetivação, que implicam a realização de mecanismos sancionatórios, terá que ser feita dentro de sua circunscrição territorial. Por exemplo, se alguém viola uma norma nacional de um país enquanto está no exterior, na ausência de qualquer cooperação interestatal, só poderá ser coagido a cumprir pena, seja civil ou criminal, quando adentrar no país que emitiu a norma.

O exemplo mais tradicional de extraterritorialidade pode ser encontrado no Direito Criminal. Neste sentido, é possível existir uma legislação que estabeleça punição de crimes realizados por nacionais no exterior, ou ainda por estrangeiros contra nacionais. Há também os casos que envolvem crimes contra altos funcionários do governo (como chefes do executivo) durante sua estada no exterior, ou que atentem, de alguma forma, contra o patrimônio do Estado, como por exemplo, na produção de danos a bens de representação diplomática. Conforme Sornarajah (2010, p. 165), nos países de tradição jurídica de raiz romano-germânica é relativamente comum dispor em seus códigos criminais a extensão extraterritorial da lei penal de acordo com estes moldes ${ }^{5}$. Na mesma linha, observa-se a existência de legislações que punem nacionais que utilizam serviços de prostituição infantil no exterior. Estas normas estabelecem que o controle de tais condutas não deva ser feito somente no local onde a prostituição existe, geralmente de estrutura estatal deficitária e ineficaz, mas também pelos países onde se originam os turistas ${ }^{6}$.

Nesse passo, não existe óbice para a elaboração de normas nacionais que permitam o controle das operações das ETNs no exterior pelos Estados de origem (investidores). Trata-se de uma alternativa interessante, uma vez que existe uma tendência natural dos países hospedeiros evitarem a regulação, principalmente por medo de perderem investimentos (SORNARAJAH, 2010,

5 Além do Brasil (art. $7^{\circ}$ ), existe legislação semelhante em Portugal (art. $5^{\circ}$ ), França (do art. 113-6 ao art. 113-12), Alemanha (título I, $\S 5^{\circ}$ ) e Argentina (art. $1^{\circ}$ ).

${ }^{6}$ É o caso da legislação na Suécia, Austrália, Canadá, Reino Unido e Estados Unidos (NICHOLS, 2000, p. 643). 
p. 169). Os principais exemplos vêm dos Estados Unidos. O Direito estadunidense permite que sejam punidas práticas anticoncorrenciais realizadas por afiliadas no exterior ${ }^{7}$, desde que causem efeitos no mercado dos EUA. Também existem leis norte-americanas nos mesmos moldes que proíbem empresas de negociarem com países considerados como inimigos (MUCHLINSKI, 2007, p. 115).

Nas últimas décadas, com base na Alien Torts Claim Act-ATCA ("Lei das Ações Cíveis Movidas por Estrangeiros"), que permite que estrangeiro ingresse com ação civil de indenização no judiciário norte-americano por descumprimento de Direito Internacional, ETNs (dos EUA e estrangeiras) estão sendo processadas nos EUA por violações de Direitos Humanos no exterior ${ }^{8}$. $\mathrm{O}$ ingresso de vários casos em cortes norte-americanas ${ }^{9}$ e as possíveis condenações decorrentes acarretariam a consolidação do controle extraterritorial da conduta destas empresas, no que diz respeito à proteção dos Direitos Humanos. Outros países seguiram o exemplo dos EUA e passaram a exercer jurisdição sobre as ações de suas ETNs no exterior a partir de construções jurisprudenciais, como é o caso da Austrália, Países Baixos e Reino Unido. Após anos de batalhas judiciais, em abril de 2013, a Suprema Corte norteamericana decidiu que a $A T C A$ não é aplicável a atos realizados no exterior, devendo o descumprimento de Direito Internacional ter ligação com o solo norte-americano, sob pena de ocorrer uma violação de soberania estrangeira, em uma tentativa de barrar o elevado número de ações propostas nos últimos anos.

7 O precedente é o caso United States v. ALCOA de 1945. Na ocasião, vários produtores de alumínio de diferentes acertaram um acordo de cartel na Suíça. Uma empresa norte-americana participou por meio de sua afiliada canadense. Apesar de o ilícito ter se consumado no exterior, a Suprema Corte entendeu que a violação da legislação antitruste praticaria efeitos diretos e substanciais nos EUA (FARIA, 1990, p. 27).

8 Neste contexto, a base jurídica está no direito costumeiro e pactício internacional voltado à proteção da pessoa humana que os Estados Unidos está submetido, como a Declaração Universal de Direitos Humanos e o Pacto Internacional de Direitos Civis e Políticos.

9 Em Doe v. UNOCAL discutiu-se a atuação de uma ETN norte-americana em Mianmar, que supostamente patrocinou torturas e trabalho forçados. Em Kiobel v. Royal Dutch Petroleum, o processo foi contra uma empresa transnacional de capital britânico e holandês pela participação em um massacre de manifestantes contra a instalação de uma fábrica em Ogani, Nigéria. Em Bowoto v. Chevron Corp. as acusações foram direcionadas a uma afiliada de empresa norte-americana também pelo uso indevido da força na Nigéria. Em Sarei v. Rio Tinto nacionais de Papua Nova Guiné processaram a empresa transnacional de origem britânica e australiana por terem apoiado ações violentas do governo. Em Wang Xiaoning v. Yahoo! chineses processaram a empresa de serviços de internet por terem repassado informações ao governo chinês, que prendeu e torturou os usuários por atividades supostamente subversivas. Em Sinaltrainal v. Coca-Cola Company os autores acusaram engarrafadores de refrigerante na Colômbia de colaborarem com as forças paramilitares em atos de violência contra membros de sindicato. 


\section{ETNS E DIREITO INTERNACIONAL: (CRÍTICA ÀS) PRO- POSTAS JÁ EXISTENTES}

O entendimento sobre a necessidade de controle das atividades das ETNs pelos países-sede não deve ser visto, contudo, como uma descoberta de uma fórmula mágica. É fácil reconhecer, em tese, a existência de uma obrigação destes países em fiscalizarem suas ETNs, difícil é operacionalizar esta afirmativa. Visto que a previsão da extraterritorialidade de suas normas é um ato unilateral que parte do próprio Estado no exercício de sua soberania, não há nada que simplesmente force a fazê-lo. Há uma forte tendência dos Estados poderosos economicamente permanecerem inertes, com objetivo de proteger as práticas comerciais de suas ETNs, ainda que estas ações prejudiquem os hospedeiros.

Conforme Nichols (2000, p. 628) existe uma dificuldade em se pensar na regulação de ETNs apenas sob a lógica exclusiva do Direito nacional. Enquanto as estruturas empresárias são formadas sem qualquer consideração com as barreiras políticas, o Direito nacional enfrenta os obstáculos fronteiriços. No mesmo sentido, Muchlinski (2007, p. 115) entende que existe um descompasso entre a amplitude gerencial e operacional das ETNs e o alcance jurisdicional do Estado que procura regulá-las. A estratégia de utilização dos Direitos nacionais aplicados de forma territorial ou extraterritorial enfrenta o problema da assimetria destas manifestações jurídicas. Não há nada o que assegure que os Estados irão efetivamente coibir estas condutas e, caso o façam, não existem garantias de que seguirão o mesmo padrão regulatório. Autilização do Direito Internacional pode representar o afastamento da dependência de medidas unilaterais estatais e a construção de um regime jurídico multilateral capaz de coibir as más condutas empresárias em qualquer lugar do mundo. Neste contexto, seriam depuradas as pretensões individualistas dos Estados quanto ao tema, buscando-se uma situação favorável para a comunidade internacional.

Historicamente, o Direito Internacional foi criado para regular a conduta dos Estados e garantir a coexistência pacífica no plano internacional (SHAW, 2010, p. 37). Difere do Direito nacional na produção e aplicação de normas, uma vez que não existe aqui um órgão externo centralizado, restando aos próprios Estados a realização da sanção, tal qual o Direito de uma sociedade primitiva ${ }^{10}$.

\footnotetext{
${ }^{10}$ Nas palavras de Weil (1983, p. 413-414), "como todo mundo sabe, o sistema normativo internacional [...] é menos elaborada e mais rudimentar que as ordens jurídicas domésticas - o que, é claro, não significa que é inferior ou menos 'jurídico' que eles: sã̃o apenas diferentes”. No direito de uma sociedade primitiva, o indivíduo que tinha seus interesses juridicamente protegidos violados estava autorizado pelo próprio ordenamento jurídico a tomar as medidas coercitivas previstas. É a autotutela ou justiça pelas próprias mãos. Com a organização da estrutura estatal, a autotutela deixou de ser permitida no direito doméstico e a sanção passou a ser aplicada por esta estrutura centralizada e externa. Não existe tal órgão nas relações entre Estados (KELSEN, 1986, p. 72).
} 
A partir de sua expansão e desenvolvimento, o Direito Internacional contemporâneo não se preocupa apenas com as relações interestatais, mas também com a conduta dos Estados frente aos indivíduos. Questões que antes eram consideradas como domésticas e submetidas apenas ao Direito interno, como Direitos Humanos e Direito Ambiental, encontram-se submetidas a normas internacionais (SHELTON, 2006, p. 162) ${ }^{11}$. Hoje, qualquer assunto pode ser suscetível de regulação pelo Direito Internacional desde que seja de interesse da comunidade internacional (KELSEN, 2010, p. 250). Neste contexto, não existem óbices para a criação de normas internacionais com objetivo de regular as ETNs.

A operacionalização desta norma, entretanto, é um desafio. Ainda que a norma internacional seja voltada para indivíduos (ou uma coletividade, no caso a empresa), não é possível afastar a figura do Estado deste processo. Não se pode esquecer que são os Estados, e não as ETNs, os sujeitos de Direito Internacional (ALVAREZ, 2011, p. 34). Conforme Shaw (2010, p. 186), a razão disso reside nas falhas que as ETNs apresentam nos principais testes para averiguação de personalidade jurídica internacional, como a capacidade de celebrar tratados internacionais, o amplo acesso a tribunais internacionais e a possibilidade de ser punida por eles. Em relação ao segundo requisito, observase que existe um acesso limitadíssimo a dois tribunais, no entanto, as ETNs participam apenas como autores e nunca como réus, o que demonstra a natureza incompleta no cumprimento do pretenso requisito ${ }^{12}$. Assim, na presença de norma internacional de matéria relacionada às ETNs são os Estados, os sujeitos internacionais, que possuem a obrigação internacional de garantir direitos e exigir deveres desta estrutura empresarial que opera em seu território, utilizandose de seus mecanismos coercitivos (NASSER, 2006, p. 90).

Não existe impedimento para que um Estado aplique diretamente uma norma internacional em ETNs. Contudo, com a expansão do Direito Internacional em direção a novos temas (tidos tradicionalmente como domésticos), é comum encontrar normas internacionais incompletas (KELSEN, 2010, p. 493), que

\footnotetext{
${ }^{11}$ Conforme Shelton (2006, p. 162) até o século XX, praticamente todos os tratados eram bilaterais e dispunham apenas de relações jurídicas interestatais, como relações diplomáticas, direito marítimo, comércio e extradição. Hoje, o número de instrumentos internacionais cresceu exponencialmente e regulam vários assuntos, geralmente de maneira multilateral.

${ }^{12} \mathrm{O}$ primeiro é o International Centre for Settlement of Investment Disputes (Centro Internacional para Arbitragem de Disputas sobre Investimentos), corte arbitral ligada ao Banco Mundial que busca resolver lides envolvendo investimento estrangeiro. O segundo é o Iran-United States Claim Tribunal, instituição criada mediante acordo entre Irã e Estada Unidos para resolver os conflitos envolvendo a nacionalização de ativos norte-americanos após a Revolução Iraniana.
} 
exigem a conversão ou criação de Direito interno, com objetivo de permitir as devidas adaptações de acordo com a realidade jurídica do Estado vinculado. Aqui, o Direito Internacional pode ser um instrumento para reforma do Direito e das instituições nacionais, possibilitando a absorção de experiências jurídicas testadas em outros países e difundidas mediante o consenso da comunidade internacional. Caso o procedimento legislativo interno não seja realizado, dita cláusula do tratado fica prejudicada até que as medidas legislativas nacionais sejam tomadas. Enquanto as normas domésticas não são criadas, cabe aos demais Estados avaliarem a situação do cumprimento do tratado e realizarem pressões políticas para que o país signatário tome as devidas providências. Um exemplo de norma internacional que carece de execução automática são os tratados que versam sobre Direito Penal e crimes transnacionais ${ }^{13}$. Incapazes de criminalizarem condutas, pois seria uma afronta à soberania nacional, limitam-se em criar a obrigação para os Estados de alterarem a sua legislação penal de acordo com o tratado, de modo a uniformizar a repressão penal frente a crimes de interesse internacional.

É necessário analisar qual fonte de Direito Internacional seria a mais adequada para tratar sobre ETNs. O costume internacional, prática reiterada de atos aceitos como Direito pelos Estados, foi a única fonte durante séculos, quando o Direito ainda era predominantemente não escrito (MALANCZUK, 1997, p. 36). Com o tempo, a partir dos processos de codificação do Direito, os Estados passaram a firmar acordos escritos estipulando normas jurídicas a serem observadas pelos signatários, na forma de tratados internacionais. Ainda que não exista hierarquia entre as duas fontes, não se pode negar que a clareza e estabilidade que é inerente a um documento escrito alçaram o tratado internacional à posição de principal recurso jurídico, vide o crescimento exponencial de número de acordos nos últimos dois séculos e o processo de codificação dos costumes internacionais. Uma norma jurídica com temática afeita às ETNs parece ser mais compatível com uma manifestação pactícia, pois bastaria o consenso dos Estados para a sua criação.

No entanto, as tentativas de criar um tratado internacional definitivo sobre a responsabilidade das ETNs fracassaram. Os tratados bilaterais de investimento, que poderiam dispor sobre o assunto, estabelecem apenas direitos às ETNs

\footnotetext{
${ }^{13}$ É o caso da Convenção das Nações Unidas contra o Crime Organizado Transnacional e seu Procolo Relativo à Prevenção, Repressão e Punição do Tráfico de Pessoas, em Especial Mulheres e Crianças; Convenção contra a Tortura e Outros Tratamentos ou Penas Cruéis, Desumanos e Degradantes; Convenção Internacional para a Proteção de Todas as Pessoas contra os Desaparecimentos Forçados; Convenção para a Supressão do Financiamento do Terrorismo, e as convenções internacionais e regionais contra a corrupção, que serão estudados com detalhes ao longo da pesquisa.
} 
(como proteção ao investimento e garantia de reparação econômica em caso de expropriação), sem a materialização de obrigações das estruturas empresárias frente ao Estado hospedeiro. Na década de 70, após o não cumprimento das promessas de desenvolvimento econômico e social do processo de liberalização do investimento estrangeiro direto, muitos países periféricos adotaram uma postura crítica em relação às ETNs, vistas como instrumento de uma dominação econômica e intervenção política (KELLER, 2008, p. 255). A propagação do modelo neoliberal nos anos 90 tornou os países mais interessados em atraírem investimento estrangeiro direto a qualquer custo e menos preocupados com as possíveis consequências negativas destes empreendimentos, o que sepultou a criação do tratado internacional.

As pesquisas realizadas nas últimas décadas têm incluído uma nova fonte jurídica de Direito Internacional, nomeada de soft law ("Direito suave" ou "flexível"). De acordo com Nasser (2006, p. 25), são normas de "linguagem vaga, ou de noções de conteúdo variável ou aberto, ou que apresentam caráter de generalidade ou principiológico que impossibilite a identificação de regras específicas e claras". Uma característica sua que contrasta com as outras normas (classificadas como hard law, "Direito duro" ou "inflexível") é o afastamento de métodos tradicionais de coerção para o seu cumprimento, fundamentados em sanções, preferindo apostar em mecanismos mais brandos, estimulando, por exemplo, a prática da mediação e conciliação (NASSER, 2006, p. 25). Por vezes, parecem não ter aplicação obrigatória, preocupando-se mais em "sugerir" ou "orientar" a melhor conduta a ser adotada pelo destinatário, capaz de produzir a menor lesão social possível, do que prever uma consequência clara para o descumprimento da norma. Apesar de o conceito não se limitar ao Direito Internacional, o soft law costuma ser associado a esta manifestação jurídica.

Shelton (2006, p. 180) classifica como soft law qualquer instrumento internacional escrito que descreve condutas e princípios importantes a serem adotados pelos Estados, sem contudo, dispor sobre sanções diretas em caso de inobservância. Ao contrário dos tratados internacionais (de natureza de hard law), são normas não vinculativas, não podendo ser exigido juridicamente o seu cumprimento pelos demais membros da comunidade internacional. Tal atributo é particularmente interessante aos Estados, que podem aderir à norma sem o medo de descobrirem-se incapazes de cumprir seus dispositivos no futuro. Aqui, destaca-se a sua flexibilidade, que não exige procedimentos formais para criação e alteração, ao contrário dos tratados internacionais. Podem ser citados como 
exemplos de normas internacionais de natureza de soft law as manifestações não obrigatórias de organizações internacionais; códigos de conduta ou "leis modelos" emitidos por estas instituições; e declarações conjuntas de vários países ao final de um encontro. O Direito Internacional Econômico e o Ambiental têm sido as principais áreas que recepcionaram as práticas de soft law (SHAW, 2010, p. 93).

Muitas normas internacionais de soft law são acompanhadas por mecanismos de monitoramento gerenciados pelos aderentes ao documento. Em um procedimento de "avaliação mútua entre pares", os Estados registram as violações e avaliam o cumprimento do soft law pelos colegas, ao mesmo tempo em que são avaliados. Ao final, discutem os desafios a serem enfrentados e as possíveis medidas a serem tomadas para o aperfeiçoamento das condutas. Isto demonstra o caráter educativo do soft law, ao invés de concentrar-se na punição dos infratores, busca meios alternativos de sanção (CHINKIN, 1989, p. 862), operando em uma zona cinzenta entre Direito e Política internacionais (MALANCZUK, 1997, p. 54). Na manutenção de um canal de diálogo e negociação, a sanção torna-se indireta, na forma de pressão e constrangimento exercido pelos demais pactuantes cumpridores da norma.

Um ponto importante diz respeito à interação dinâmica entre o soft law e os instrumentos pactícios. É comum a edição prévia de normas de soft law como teste de aceitação de regras e princípios para depois elaborar um tratado internacional sobre o assunto. Outra função interessante é a criação de tratados internacionais que estipulam apenas aspectos jurídicos gerais, deixando para o soft law o seu detalhamento (SHELTON, 2006, p. 181). Evita-se, assim, o desgaste político na elaboração de emendas ou um novo instrumento pactício, deixando o Direito Internacional mais flexível, dinâmico e adaptável às mudanças. É imperativo ressaltar que o soft law também conserva o mesmo ímpeto transformador dos tratados internacionais em relação as ordens internas dos países vinculados, podendo estimular o surgimento de novas experiências de Direito nacional.

Os movimentos contestadores da década de 70 podem não ter sido capazes de criar um tratado internacional, mas impulsionaram o desenvolvimento de soft law inédita sobre o assunto. Em 1976, a OCDE elaborou as "Diretrizes para Empresas Multinacionais". No ano seguinte, foi criada a "Declaração Tripartite de Princípios sobre Empresas Multinacionais e Política Social" da OIT, que possui como objetivo difundir o respeito ao Direito do Trabalho pelas ETNs. Em 2003, a ONU criou as "Normas sobre a Responsabilidade das 
Empresas Transnacionais e Outros Empreendimentos em Relação aos Direitos Humanos". Tais normas de soft law dispõem sobre o dever dos Estados em proteger pessoas de violações de Direitos Humanos praticados por empresas, inclusive atos ilícitos produzidos no exterior, no que tange às ETNs domiciliadas em seu território.

Muchlinski (2007, p. 110) observa que, no que diz respeito à temática de regulação da conduta de ETNs, existe uma predominância no uso do soft law em comparação com os tratados internacionais. O autor defende que esta escolha não é arbitrária e segue interesses econômicos dos Estados investidores. Em temas sensíveis para este grupo, como comércio internacional e investimento estrangeiro direto, as fontes jurídicas apresentam natureza formal e obrigatória (hard law), como é o caso dos instrumentos bilaterais de proteção ao investimento estrangeiro direto. Em outra banda, no que se refere às questões ligadas à responsabilidade das ETNs frente às sociedades onde atuam, predominam-se fontes de caráter informal e de observância facultativa no plano internacional (soft law).

O que transparece é que as potências dominantes das relações internacionais apesar de exigirem práticas de responsabilidade corporativa no seu ambiente interno, relutam em garantir que suas ETNs não vão se comportar de maneira inadequada nos Estados hospedeiros, com medo que isto possa prejudicar seus interesses comerciais (KAMMINGA; ZIA-ZARIF, 2000, p. 78). A cobrança crescente da sociedade civil internacional, cada vez mais consciente da má conduta das ETNs, culminou na criação de algumas experiências normativas de natureza de soft law. Tais iniciativas, no entanto, parecem, por vezes, ser "cortinas de fumaça" para mascarar o problema, uma vez que os países ricos evitam claramente o reconhecimento de responsabilidade empresária por meio de normas imperativas de hard law (SORNARAJAH, 2010, p. 146-149). Na mesma linha e em tom crítico, Adeyeye (2007, p. 39) reconhece que a soft law podem ser inadequada e ineficiente no campo da responsabilidade das ETNs, necessitando-se de hard law nesta área.

\section{AUTORREGULAÇÃO: NOVO PARADIGMA PARA A NOR- MATIZAÇÃO DACONDUTA DAS ETNS}

Uma análise descuidada encerraria com as fontes tradicionais de Direito. No entanto, é inegável que o fenômeno jurídico possui novas e complexas nuances na contemporaneidade, que impactarão diretamente nas estratégias 
regulatórias envolvendo condutas das ETNs. Como se sabe, a formação dos Estados nacionais implicou a reivindicação do monopólio da criação do Direito (nacional ou interno) por estas estruturas. No plano externo, este esquema também é reproduzido, pois os Estados reservaram a prerrogativa de serem os produtores de suas próprias normas jurídicas. Hoje, este modelo tradicional é claramente tensionado pelos processos econômicos, políticos e sociais. Agradual integração e interdependência dos mercados nacionais e a proliferação do modelo capitalista neoliberal a partir da globalização propõem um Estado mínimo e de pouca intervenção, capaz de transferir uma série de responsabilidades do setor público para o setor privado (TEUBNER, 2012, p. 393), incluindo a produção e aplicação das normas jurídicas.

O processo contemporâneo de "privatização" do Direito vincula-se às ideias de pluralismo jurídico e de policontexturalidade, as quais contemplam possibilidades de existência de ordens jurídicas não estatais, administrado pelos próprios atores privados, que são responsáveis pela produção e aplicação das próprias normas, em uma espécie de "autorregulação" de suas condutas. Não se trata de aceitar um modelo necessariamente economicista e conduzido por agentes de mercado, mas reconhecer a existência e importância de normas espontâneas e descentralizadas, fruto do exercício da autonomia social e baseadas em ações consensuais. Tais normas estão, em princípio, desprendidas de processos políticos centralizadores das estruturas estatais, passando a ser geridas pela própria sociedade civil (TEUBNER, 2012, p. 399, 421), situação que as aproxima das necessidades de diferentes segmentos sociais.

É importante dizer que este possível "Direito não estatal" não se encontra isolado de outros sistemas jurídicos (Direito nacional e internacional) e sociais (como por exemplo, economia e política), recebendo estímulos externos. Isto é comprovado com a difusão da noção de compliance no mundo dos negócios, fenômeno com consequências relevantes para o Direito. Certamente influenciado pelas ideias contemporâneas de responsabilidade empresária e boa governança, compliance advém do verbo da língua inglesa to comply, que, em linhas gerais, significa "cumprir" ou "estar em conformidade" com algo, sendo comumente utilizado no ambiente empresarial como "cumprimento de norma jurídica". A ideia é criar mecanismos, dentro da empresa para assegurar o "cumprimento prévio" de normas jurídicas estatais, de modo a diminuir o risco de ser punido no futuro em alguma jurisdição. A cultura do compliance é implementada por meio de um "programa", um conjunto de ações planejadas por uma organização para assegurar, mediante criação de estruturas e 
mecanismos, o seguimento de uma certa conduta. Órgãos de fiscalização para a responsabilidade empresária (como no âmbito ambiental, tributário, anticorrupção, etc.) de diversos países costumam abrandar suas sanções frente a comprovação da existência de efetivos programas de conformidade (compliance), como uma maneira de estímulo ao processo de "privatização" da regulação e aplicação do Direito.

Apesar de muitas vezes originar-se de um estímulo externo, qual seja, uma tentativa de escapar das tradicionais sanções estatais, o desenvolvimento de programas de compliance conduzem a um processo de autorreprodução de um subsistema jurídico próprio, composto por normas jurídicas e suas respectivas sanções, criada e administrada por uma determinada organização empresária. No que tange às ETNs, devido a amplitude de suas atividades, este sistema de regulação não estatal adquire dimensões globais (MUCHLINSKI, 2007, p. 113), atingindo os funcionários destas empresas e seus parceiros comerciais.

A base de um programa de compliance costuma ser a manutenção de um código de conduta e ética elaborado por uma determinada empresa e direcionado aos seus funcionários. Em 1977, a General Motors era a maior ETN com atuação na África do Sul durante o regime do apartheid. À época articulava-se um forte movimento de desinvestimento no país para pressionar uma reforma política na região. O reverendo Leon Sullivan, membro do conselho de administração da companhia, ofereceu uma alternativa: a criação de um código de conduta interno que impedisse práticas racistas. O conjunto de princípios, conhecidos como Sullivan Principles, foi bem recebido pelo mundo empresarial, tendo sido reproduzido em vários códigos de conduta. Outra iniciativa semelhante foi o MacBride Principles, voltados ao respeito aos direitos dos trabalhadores na Irlanda no Norte (1984). Uma das primeiras ETNs a possuírem um código próprio foi a britânica Royal Dutch Shell. (EINHORN, 2007, p. 537-538). Hoje, várias ETNs mantêm os seus códigos. Tais normas também são comumente reproduzidas em contratos com seus parceiros comerciais, com o objetivo de alcançar também suas condutas. Estes códigos e os respectivos mecanismos de monitoramento estão revestidos de juridicidade, uma vez que descrevem condutas a serem observadas, tornando-se uma espécie de "lei interna", de cumprimento obrigatório no âmbito da empresa (incluindo ETNs). A possível sanção para o descumprimento desta norma reside em medida disciplinar (como advertência, suspensão ou demissão das ETNs) aplicada pela empresa em seu funcionário ou rompimento de contrato, quando se tratar de um parceiro comercial. 
Robé (1997, p. 62-65) fornece como exemplo a previsão no Código de Trabalho francês (Code du Travail) da possibilidade de manutenção de "regulamentos internos" (règlements intérieurs) por empresa. Seria a prova de reconhecimento, por parte do direito estatal francês, da validade jurídica dos códigos empresariais internos. O autor observa, contudo, que nas últimas décadas esta delegação legislativa tem perdido espaço, sendo permitida nos dias atuais apenas para grandes empresas e em assuntos restritos (disciplina, higiene e segurança).

Observa-se que cada ETN, com seus programas de compliance e códigos de conduta em geral, constitui um subsistema jurídico único. Contudo, além das interações com os sistemas tradicionais de Direito (Direitos nacionais), existe uma interação entre as próprias empresas que, por meio de ações em conjunto, podem conduzir a uma uniformização destes Direitos não estatais. Teubner (2003, p. 11-13) aponta que os atores privados podem criar laços transnacionais e elaborarem um Direito totalmente independente das estruturas estatais e de aplicação global (um "Direito global" ou "anacional”, em oposição a um Direito "inter-nacional”, entre Estados). Dois exemplos podem ser citados de um Direito não estatal de alcance transnacional (TEUBNER, 2003, p. 11). O primeiro é a nova lex mercatoria, representada pelo conjunto de normas criadas de maneira independente pelas empresas para a prática do comércio internacional na contemporaneidade, baseando-se nos usos e costumes comerciais reconhecidos mundialmente. Manifesta-se na elaboração e difusão de "contratos padronizados" (incoterms), idealizados e atualizados pela Câmara Internacional do Comércio, organização internacional não governamental mantida pelo meio empresário. O outro exemplo é o Direito desportivo internacional (lex sportiva internationalis), organizado pelas entidades esportivas privadas internacionais, como a Federação Internacional de Futebol (FIFA). Enquanto o Estado representa um ente estranho a estes temas e repleto de limitações em seu alcance (como o princípio da territorialidade), os agentes produtores destas normas estão plenamente inseridos em seus segmentos sociais, o que torna esta manifestação jurídica deveras atrativa.

É importante dizer que a autorregulação e a possibilidade de aplicação de um "Direito não estatal" pelas ETNs não são, absolutamente, livres de críticas. Apesar de sua existência ser reconhecida nas pesquisas contemporâneas, sua eficácia costuma ser amplamente questionada, de modo a colocá-la sempre submissa a um Direito estatal nacional. Nesse sentido, Murphy (2005, p.44-53), 
ao tratar da autorregulação de ETNs, não desvincula este sistema jurídico da necessidade de intervenção estatal. $\mathrm{O}$ autor defende que é imprescindível que os Estados estipulem oficialmente os parâmetros mínimos para a autorregulação, fiscalizem se as empresas estão efetivamente aplicando seus códigos de conduta e concedam algum tipo de benefício para aquelas que demonstrarem cumprimento de suas normas, como uma diminuição de pena em caso de sanção estatal ou um acordo favorável. Se isso não for feito, os códigos de conduta e os mecanismos de compliance viram meros instrumentos de retórica. Muchlinski (2007, p. 113) em seu turno, critica abertamente as propostas de autorregulação, taxando-as de neoliberais. Sua denúncia é no sentido de que se trata claramente de uma estratégia para retirar os Estados de alguns setores de regulação, substituindo-os por regramentos gerenciados pelas próprias ETNs, condizentes com os próprios interesses destas organizações empresárias e do capital internacional.

\section{CONSIDERAÇÕES FINAIS}

As modificações drásticas, decorrentes das potencializações que as tecnologias de informação, comunicação, transporte, produção e controle de processos, são características da atualidade. Tais transformações desafiam os postulados modernos atinentes à Política e ao Direito: monopólio estatal das normatividades política e jurídica; supremacia geopolítica do Estado para tutelar bens jurídicos socialmente considerados relevantes; dentre outros.

É importante analisar também juridicamente a emergência das ETNs, atores privados econômica e politicamente abrangentes em âmbito global. Não se trata de ter de desconsiderar a importância estatal na normatização e tutela das suas condutas: muitas vezes o Estado é meio de garantia de atenção aos interesses das próprias ETNs. Ademais, é também do Estado que elas dependem para se instalarem, funcionarem e produzirem legal e legitimamente, demonstrando-se não haver um esvaziamento da sua função normativa. Todavia, repensar seu papel conforme a policontexturalidade e a hipercomplexidade, a fim de que não se estanquem e obliterem as possibilidades regulatórias públicas significativas, é mister.

De outra banda, mesmo tendo se revelado mal sucedidas até hodiernamente as experiências regulatórias das ETNs pelo Direito Internacional, este âmbito também possui sua importância normativa relevante. Analisar tais estratégias, seus sucessos, fracassos e condições de operabilidade, não é 
contraproducente para a questão da regulação das corporações atuantes de maneira fluida no cenário global.

A própria complexificação dos processos normativos internos das ETNs - decorrentes, muitas vezes, dos próprios processos sociais reflexivos (pressão da sociedade sobre tais empresas; atuação empresarial negocial) - é especializada e impõe econômica e juridicamente. Desconsiderar, assim, a importância da sua autorregulação é postura teórica totalmente alheia em relação ao ambiente social em que o Direito se encontra. Negar o pluralismo jurídico é negar a própria reflexividade entre Direito e sociedade.

Tem-se, por fim, que apesar da necessidade de mais pesquisas acerca deste tema, pode-se considerar que a regulação das ETNs se encontra em um ambiente social complexo, em que comunicações normativas multifatoriais reflexivas entre Estado, organizações internacionais e os próprios entes econômicos privados globais a serem regulados devem ser estabelecidas e analisadas. Trata-se de elevar qualitativamente a análise do Direito em sociedade ao nível de complexidade que os processos sociais atuais exigem.

\section{REFERÊNCIAS}

ADEYEYE, Adefolake. Corporate Responsibility in International Law: Which Way to Go? Singapore Yearbook of International Law, Singapore, v. 11, p. 141-161, 2007.

ALVAREZ, Jose E. Are Corporations "Subjects" of International Law? Santa Clara Journal of International Law, Santa Clara, v. 9, n. 1, p. 1-36, 2011.

BAUMAN, Zygmunt. Vidas Desperdiçadas. Tradução de Carlos Alberto Medeiros. Rio de Janeiro: Jorge Zahar Editores, 2005.

BROWNLIE, Ian. Princípios de Direito Internacional Público. Lisboa: Fundação Calouste Gulbenkian, 1997.

CHINKIN, C. M. The Challenge of Soft Law: Development and Change in International Law. International and Comparative Law Quarterly, Cambridge, v. 38, p. 850-866, 1989. 
DELEUZE, Gilles. Post-scriptum sobre as sociedades de controle. In: DELEUZE, Gilles. Conversações. Tradução de Peter Pál Pelbart. São Paulo: Editora 34, 2007.

DEVA, Surya, Regulating Corporate Human Rights Violations:

Humanizing Business. New York: Routledge, 2012.

EHRLICH, Eugen. Fundamentos da Sociologia do Direito. Brasília: UNB, 1986.

EINHORN, Aaron. The Evolution and Endpoint of Responsibility: The FCPA, SOX, Socialist-Oriented Governments, Gratuitous Promises, and a Novel CSR Code. Denver Journal of International Law and Policy, Denver, v. 35, p. 509-545, 2007.

FARIA, José Ângelo Estrella. A Aplicação Extraterritorial do Direito da Concorrência. Revista de Informação Legislativa, Brasília, v. 27, n. 105, p. 19-46, 1990.

FOUCAULT, Michel. Soberania e Disciplina. In: FOUCAULT, Michel. Microfísica do Poder. Org. e trad. Roberto Machado. 20. ed. São Paulo: Graal; Editora Paz e Terra, 2004.

GÜNTHER, Gotthard. Life as Poly-Contexturality. Vorkender, fev. 2004. Disponível em: $<$ http://www.vordenker.de/ggphilosophy/ gg_life_as_polycontexturality.pdf>. Acesso em 13 abr 2015.

GUZMAN, Andrew. Why LDCs Sign Treaties That Hurt Them? Virginia Journal of International Law, Charlottesville, v. 38, p. 640-688, 1998.

KAMMINGA, Menno T.; ZIA-ZARIF, Saman. Introduction. In: KAMMINGA, Menno T.; ZIA-ZARIF, Saman (Org.). Liability of Multinational Corporations under International Law. Haia: Kluwer Law International, 2000. p. 1-16.

KELLER, Helen. Codes of Conduct and Their Implementation: the Question of Legitimacy. In: WOLFRUM, Rüdger; VOLKER, Röben (Org.). 
Legitimacy in International Law. Berlin: Springer, 2008. p. 219-298.

KELSEN, Hans. Derecho y paz en las relaciones internacionales. 2. ed. Mexico: Fondo de Cultura Económica, 1986.

. Princípios do Direito Internacional. Ijuí: Unijuí, 2010.

LUHMANN, Niklas. Como se pueden observar estructuras latentes? In: WATZLAWICK, Pal; KRIEG, Peter. El ojo del observador: contribuciones al construtivismo. Barcelona: Gedisa, 1995.

. La ciencia de la sociedad. Tradução de Silvia Pappe, Brunhilde Erker e Luis Felipe Segura, sob a coordenação de Javier Torres Nafarrate. México: Universidad Iberoamericana/ ITESO/Anthropos, 1996.

. Law as a Social System. Tradução para o inglês de Klaus A.

Ziegert. Oxford: Oxford University Press, 2004.

MACEDO, Stephen. The Princeton Principles on Universal Jurisdiction. Princeton: Princeton, 2001.

MALANCZUK, Peter. Akehurst's Modern Introduction to

International Law. 7. ed. New York: Routledge, 1997.

MUCHLINSKI, Peter T. Multinational Enterprises and the Law. 2 ed. Oxford: Oxford University Press, 2007.

MURPHY, Sean D. Taking Multinational Corporate Codes of Conduct to the Next Level. Columbia Transnational Law, New York, v. 43, p. 1-55, 2005.

NASSER, Salem Hikmat. Fontes e Normas do Direito Internacional: um estudo sobre a Soft Law. 2. ed. São Paulo: Atlas, 2006.

NEVES, Marcelo. Transconstitucionalismo. São Paulo: WMF Martins Fontes, 2009. 
NICHOLS, Philip M. The Myth of Anti-Bribery Laws as Transnational Intrusion. Cornell International Law Journal, Ithaca, v. 33, p. 627-655, 2000 .

PIETH, Mark. Article 4: Jurisdiction. In: PIETH, Mark; LOW, Lucinda A.; CULLEN, Peter J. The OECD Convention on Bribery: A Commentary. Cambridge: Cambridge University Press. 2007. p. 267-288.

ROBÉ, Jean-Philippe. Multinational Enterprises: The Constitution of a Pluralistic Legal Order. In: TEUBNER, Gunther (Org.). Global Law Without a State. Vermont: Dartmouth, 1997. p. 45-77.

ROBINSON, Mary. Foreword. In: MACEDO, Stephen (Org.). The Princeton Principles on Universal Jurisdiction. Princeton: Princeton, 2001. p. 15-18.

ROCHA, Leonel Severo. A Produção Autopoética do Sentido do Direito. Direitos Culturais, Santo Ângelo, v. 4, n. 7, p. 13-26, 2009.

. Epistemologia jurídica e democracia. 2. ed. São Leopoldo: Editora Unisinos, 2003.

ROCHA, Leonel Severo; ATZ, Ana Paula. Do pluralismo jurídico ao diálogo inter-sistêmico das fontes na sociedade mundial. In: PEREIRA, Agostinho Oli Koppe; HORN, Luiz Fernando Del Rio (Orgs.). Relações de consumo: globalização. Caxias do Sul: Educs, 2010. p. 107-132.

SORNARAJAH, M. The International Law of Foreign Investment. Cambridge: Cambridge University Press, 2010.

SANTOS, Boaventura de Sousa. A Crítica da razão indolente: Contra o Desperdício da Experiência. São Paulo: Cortez, 2000.

. Notas sobre a História Jurídico-Social de Pasárgada. In: SOUZA Jr., José Geraldo (Org.). O Direito Achado na Rua. Brasília: UNB, 1987. p. $45-51$. 
SHAW, Malcolm N. Direito Internacional. São Paulo: Martins Fontes, 2010.

SHELTON, Dinah. International Law and 'Relative Normativity'. In: EVANS, Malcolm (Org.). International Law. 2 ed. Oxford: Oxford University Press, 2006. p. 159-184.

TEUBNER, Gunther. A Bukowina Global sobre a Emergência de um Pluralismo Jurídico Transnacional. Impulso, Piracicaba, v. 13, n. 33, p. 9-31, 2003.

. Autoconstitucionalização de corporações transnacionais? Sobre a conexão entre os códigos de conduta corporativos (Corporate Codes of Conduct) privados e estatais. Tradução de Ivar Hartmann. Revisão de Germano Schwartz. In: SCHWARTZ, Germano (Org.). Juridicização das esferas e fragmentação do direito na sociedade contemporânea. Porto Alegre: Livraria do Advogado, 2012.

. After Privatization? The Many Autonomies of Private Law.

Current Legal Problems, London, v. 51, n. 1, p. 393-424, 2012.

WEIL, Prosper. Towards Relative Normativity in International Law? The American Journal of International Law, Washington, v. 77, n. 3, p. 413442, 1983.

WELSCH, Wolfgang. Reason and Transition: on the Concept of Transversal Reason. 29 out. 2000. Disponível em: <http:/www2.uni-jena.de/ welsch/Papers/reasTrans.html>. Acesso em 13 abr 2015. Informação postada no site Prof. Dr. Wolfgang Welsch, no menu Online Texts \& Publication abstracts: Reason and transition.

WILKE, Helmut. Reflexivo (Direito). Tradução para o francês de Hugues Dumont. In: ARNAUD, André-Jean (Dir.). Dicionário Enciclopédico de Teoria e de Sociologia do Direito. Rio de Janeiro: Renovar, 1999.

WILKINS, Mira. European and North American Multinationals. 1870-1914: Comparions and Contrasts. In: JONES, Geoffrey (Org.). Transnational 
Corporations: a Historical Perspective. London: Routledge, 1992, p. 23-62.

WOLKMER, Antonio Carlos. Pluralismo Jurídico: Fundamentos de uma nova cultura no Direito. 3. ed. São P 1 au lo: Editora Alfa Omega, 2001.

Como citar: FORNASIER, Mateus de Oliveira; FERREIRA, Luciano Vaz. Empresas transnacionais e regulação jurídica: da lógica estatal às ordens jurídicas não-estatais. Scientia Iuris, Londrina, v.19, n.2, p.73-100, dez.2015. DOI: $10.5433 / 2178-8189.2015 v 19 n 2 p 73$. ISSN 2178-8189. 